\title{
Lymphocyte subset abnormalities in early diffuse cutaneous systemic sclerosis
}

David A. Fox ${ }^{1 *}$ D, Steven K. Lundy ${ }^{1}$, Michael L. Whitfield ${ }^{2}$, Veronica Berrocal ${ }^{3,4}$, Phillip Campbell ${ }^{1}$, Stephanie Rasmussen ${ }^{1}$, Ray Ohara', Alexander Stinson ${ }^{1}$, Mikel Gurrea-Rubio ${ }^{1}$, Evan Wiewiora ${ }^{4}$, Catherine Spino ${ }^{4}$, Erica Bush ${ }^{1}$, Daniel Furst ${ }^{5}$, Shiv Pillai ${ }^{6}$ and Dinesh Khanna ${ }^{1}$

\begin{abstract}
Background: Abnormalities in lymphocyte surface markers and functions have been described in systemic sclerosis (SSc), but conflicting results abound, and these studies often examined patients with heterogeneous disease duration, severity, clinical phenotype, and concurrent immunosuppressive agents. We studied a clinically homogeneous group of early diffuse cutaneous SSc patients not exposed to immunosuppressive drugs who were enrolled in a clinical trial and compared their immune parameters to healthy control subjects.

Methods: Lymphocyte subsets were enumerated by multi-parameter flow cytometry of peripheral blood mononuclear cells at baseline visit. Production of the cytokines IL-4 and IL-17 was measured by intracellular flow cytometry following $T$ cell activation.

Results: SSc patients had increased percentages of CD4+ T cells but lower percentages of CD8+ T cells versus controls. The CD28-negative population was expanded in SSc, in the CD4 subset. Striking expansion of CD319+ T cells was noted among the CD4+ cells, in which they were barely detectable in healthy subjects. Frequencies of IL4 producing cells did not differ between SSC and controls, but expansion of IL-17 producing cells was observed in SSc. A higher proportion of CD319+ cells produced cytokines, compared to other CD4+ cells. Numbers of activated $\mathrm{T}$ cells, regulatory T cells, and B cells were similar in SSc and control groups. Circulating follicular helper but not peripheral helper T cells were slightly expanded in SSc.

Conclusion: In this carefully selected group of early diffuse cutaneous SSc patients, analysis of immune cell parameters has identified abnormalities that likely reflect disease pathogenesis and that are candidate biomarkers for sub-classification and targeted treatment. The CD4+CD319+ (SLAM-F7+) cells are cytotoxic and oligoclonal, were recently shown to be a dominant T cell population in perivascular lymphocytic infiltrates in SSc skin, actively secrete cytokines, and are emerging as a target for novel treatments of SSC.
\end{abstract}

Keywords: Systemic sclerosis, Autoimmunity, CD4 T cells, Interleukin, CD319

\footnotetext{
* Correspondence: dfox@umich.edu

'Division of Rheumatology, Department of Internal Medicine, Scleroderma

Program, Clinical Autoimmunity Center of Excellence, University of Michigan, Ann Arbor, MI, USA

Full list of author information is available at the end of the article
}

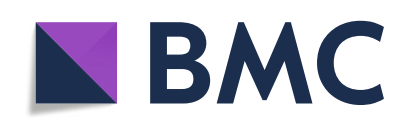

(๑) The Author(s). 2021, corrected publication 2021. Open Access This article is licensed under a Creative Commons Attribution 4.0 International License, which permits use, sharing, adaptation, distribution and reproduction in any medium or format, as long as you give appropriate credit to the original author(s) and the source, provide a link to the Creative Commons licence, and indicate if changes were made. The images or other third party material in this article are included in the article's Creative Commons licence, unless indicated otherwise in a credit line to the material. If material is not included in the article's Creative Commons licence and your intended use is not permitted by statutory regulation or exceeds the permitted use, you will need to obtain permission directly from the copyright holder. To view a copy of this licence, visit http://creativecommons.org/ licenses/by/4.0/. The Creative Commons Public Domain Dedication waiver (http://creativecommons.org/publicdomain/zero/1. 0/) applies to the data made available in this article, unless otherwise stated in a credit line to the data. 


\section{Background}

Systemic sclerosis (SSc) is a complex multisystem disease characterized by autoimmunity, vascular dysfunction/damage, and fibrosis of target organs that may include the skin, lung, heart, kidney, and gastrointestinal tract [1]. CD4+ T cells are central to the pathogenesis of a range of autoimmune diseases, both through their role in activating B cell differentiation and autoantibody production and through secretion of cytokines. Substantial evidence supports the concept that $\mathrm{T}$ cells play a key role in the pathogenesis of early SSc, including cutaneous disease, and at least some of the visceral complications. Skin biopsies obtained from SSc patients early in their disease demonstrate a perivascular, mononuclear cell infiltrate comprised of $\mathrm{T}$ cells and macrophages [2]. $\mathrm{T}$ cells are the dominant population of lymphocytes in the skin and are activated [3]. T cell infiltration correlates with skin involvement, suggesting a relation between inflammation and fibrosis [4]. Recent data using nextGen RNA Sequencing in 57 subjects with early diffuse cutaneous SSc (dcSSc, mean disease duration of 1.3 years) shows that the adaptive immune system signature was present in a majority of the subjects: CD8+ T cell, $\mathrm{CD} 4+\mathrm{T}$ cell, and B cell signatures were present in $67 \%$, $61 \%$, and $67 \%$ of patients, higher than previously published data in long-standing disease [5].

Many issues remain unresolved about the roles of various lymphocyte subsets in the pathogenesis of SSc, including the importance of Th17 and Th2 effector cell subsets of CD4+ T cells, defects in regulatory $\mathrm{T}$ cell numbers and function, and whether other $\mathrm{T}$ or $\mathrm{B}$ cell subsets differ meaningfully from their numbers and function in healthy controls. These uncertainties may in part arise from a study of patients with heterogeneous duration of disease, different forms of SSc, and prior or ongoing exposure to cytotoxic immunosuppressive drugs and biologic agents.

We sought to define the lymphocyte profile of early $\mathrm{dcSSc}$ in patients whose immune parameters were not confounded by a variable degree of internal organ involvement, long disease duration, or effects of medications. We therefore studied subjects enrolled in a phase 2 trial of abatacept in early dcSSc, comparing their baseline lymphocyte subsets and effector $\mathrm{T}$ cell function to healthy control lymphocytes that were analyzed concurrently. Multiple abnormalities were observed in dcSSc, notably an expanded population of CD4+CD319+ lymphocytes that may play an important role in the early pathogenesis of SSc.

\section{Methods}

\section{Study participants}

Patients with dcSSc were participants in the ASSET study, which was a randomized placebo-controlled double-blind trial of abatacept [6]. Blood samples were collected at baseline, 1 month, 3 months, and 6 months during the course of the ASSET study. The data reported herein encompass baseline analyses of lymphocyte subsets from all 88 patients enrolled in this trial.

Clinical results of the ASSET study have been reported [6]. Briefly, key inclusion criteria were [1] adult participant, age 18 and older [2]; diagnosis of SSc, as defined using the 2013 American College of Rheumatology/European Union League Against Rheumatism classification of SSc [7], and dcSSc, as defined by LeRoy and Medsger [8]; and [3] disease duration of $\leq 36$ months (defined as time from the first non-Raynaud phenomenon manifestation). Oral corticosteroids $(\leq 10 \mathrm{mg} /$ day of prednisone or equivalent) and NSAIDs were permitted if the patient was on a stable dose regimen for $\geq 2$ weeks prior to and including the baseline visit, but no background immunomodulatory therapies were allowed. Written informed consent was obtained from each participant. All study procedures were approved by institutional IRBs.

A group of 25 healthy controls was studied concurrently, specifically for the analyses contained in this report. These study participants were sex-matched and similar in age to the SSc patients (Tables 1 and 2).

\section{Collection and processing of samples}

Peripheral blood was collected in heparinized tubes at participating clinical sites and shipped in insulated containers for overnight delivery to the University of Michigan. Peripheral blood collected at the University of Michigan was left overnight at room temperature prior to processing. PBMCs were isolated from heparinized peripheral blood using Histopaque-1077 (Sigma-Aldrich) density gradient centrifugation and washed three times in PBS containing 2\% FBS. Aliquots of PBMCs were cryopreserved in FBS containing 10\% DMSO and stored in liquid nitrogen until use.

\section{Cell culture}

Cryopreserved PBMCs were thawed in a water bath and suspended in RPMI-1640 containing 10\% FBS. Cells for the Th2/Th17 analysis panel (Supplementary Table 1) were plated into 12-well cell culture plates (Corning) pre-coated with anti-CD3 antibody (OKT3) at $1 \times 10^{6}$ cells per well. Anti-CD28 (CD28.2, $5 \mu \mathrm{g} / \mathrm{ml})$ was added to the wells and the cells were incubated for $24 \mathrm{~h}$ at

Table 1 Demographics of the SSc patients and control subjects

\begin{tabular}{llll}
\hline & Control & SSc & $\boldsymbol{p}$ value \\
\hline Female & 20 & 66 & $>0.05$ \\
Male & 6 & 22 & $>0.05$ \\
Mean age (range) & $42(22-70)$ & $49(18-73)$ & $<0.01$ \\
\hline
\end{tabular}


Table 2 Demographic and baseline disease characteristics of the SSc patients

\begin{tabular}{|c|c|}
\hline & Overall $(N=88)$ \\
\hline Age, years, mean (SD) & $49(13)$ \\
\hline Female, N (\%) & $66(75 \%)$ \\
\hline White, $N(\%)$ & $72(82 \%)$ \\
\hline Not Hispanic or Latino, N (\%) & $76(86 \%)$ \\
\hline Disease duration, years*, mean (SD) & $1.59(0.81)$ \\
\hline Disease $\leq 18$ months, $N(\%)$ & $53(60 \%)$ \\
\hline mRSS, mean (SD) & $22.45(7.65)$ \\
\hline FVC\% predicted, mean (SD) & $85.4(15.10)$ \\
\hline DLCO\% predicted, corrected for Hgb, mean (SD) & $78.0(18.24)$ \\
\hline Patient global assessment, mean (SD) [theoretical range 0-10] & $4.09(2.38)$ \\
\hline HAQ-DI, mean (SD) [theoretical range 0-3] & $1.05(0.71)$ \\
\hline Physician global assessment, mean (SD) [theoretical range 0-10] & $4.77(1.67)$ \\
\hline Tendon friction rubs, $N(\%)$ & $32(36 \%)$ \\
\hline Large joint contractures, $N(\%)$ & $63(72 \%)$ \\
\hline Swollen joint count, mean (SD) [theoretical range 0-28] & $3.75(5.70)$ \\
\hline Proportion of participants with $\geq 1$ swollen joint count, $N(\%)$ & $42(48 \%)$ \\
\hline Previous use of immunosuppressives, $N(\%)$ & $12(14 \%)$ \\
\hline Use of prednisone, $N(\%)$ & $12(14 \%)$ \\
\hline
\end{tabular}

mRSS modified Rodnan skin score, FVC forced vital capacity, DLCO diffusion capacity of carbon monoxide

*Disease onset was defined as the first non-Raynaud's sign or symptoms

$37^{\circ} \mathrm{C}$. Brefeldin A $(5 \mu \mathrm{g} / \mathrm{ml})$ was added at $20 \mathrm{~h}$. The remaining PBMCs not plated for the Th2/Th17 panel were used immediately for flow cytometry staining.

\section{Preparation and staining of cells for flow cytometry}

PBMCs were washed in flow buffer (PBS containing $0.2 \%$ BSA and $5 \mathrm{mM}$ EDTA), passed through a cell strainer $(40-\mu \mathrm{m}$ pore, Corning) to remove aggregates, and plated at $5 \times 10^{5}$ cells per well in 96-well conical bottom plates (Nunc) on ice. Cells were treated with human FcR blocking reagent (Miltenyi Biotec) and DAPI (4',6-Diamidino-2-Phenylindole, Dihydrochloride, Invitrogen) or Zombie Violet ${ }^{\mathrm{TM}}$ (Biolegend) for $15 \mathrm{~min}$ on ice and then washed three times in flow buffer prior to antibody labeling. Cell surface molecules were stained with antibodies (Supplementary Table 1) for $20 \mathrm{~min}$ on ice, washed twice in flow buffer, and resuspended in $2 \%$ formalin $(0.2 \mathrm{ml})$. Cells for intracellular (IC) staining were treated with IC fixation and permeabilization buffer (eBioscience) prior to staining. Cells were stained with IC antibodies (Supplementary Table 1) in IC fixation and permeabilization buffer for $20 \mathrm{~min}$ at room temperature. Cells were washed in flow buffer then transferred to 96-well Micronics plates for analysis.

\section{Data analysis}

Flow cytometry was conducted using an LSR I Fortessa flow cytometer (BD Biosciences) with FACSDiva software. Five thousand single color bead controls were recorded and compensation values for each parameter were set. Flow data were analyzed with FlowJo (v10).

Lymphocytes were selected from the center population of PBMCs in the Forward Scatter-Area (FSC-A) vs Side Scatter-Area (SSC-A) plane. From the lymphocyte population, single cells were identified in the FSC-A vs. Forward Scatter-Height (FSC-H) plane. From the unstained control, a gate was set around all cells in the 450/50 (405)-Area vs SSC-A plane to determine live cells and applied to all other samples. For analyses of $\mathrm{T}$ cell populations, cells were then gated on CD3 using the CD3 Fluorescence minus one (FMO) to determine gating. For analyses of B lymphocytes, the live singlet lymphocytes were gated as CD19+ cells. Additional gating for subsets within the $\mathrm{T}$ and $\mathrm{B}$ cell populations were determined based on FMO staining for each of the markers.

Statistical comparisons of patient versus control groups were performed using the Student $t$ test. For non-normally distributed data, the Wilcoxon rank-sum test was also used.

\section{Results}

The mean age for the 88 SSc patients was 49 (range 18$73)$ years, 66 (75\%) were female, and mean disease duration (from 1st non-Raynaud's phenomenon) was 1.59 years. The healthy controls were $77 \%$ female and were 
slightly younger than the SSc patients (mean age 42, range 22-70).

Flow cytometry of peripheral blood mononuclear cells, gated on lymphocytes, showed a higher percentage of CD4+ cells in SSc compared to controls. Conversely, the percentage of CD8+ cells was lower in SSc compared to controls (Fig. 1a). SSc patients had a higher percentage of CD28-CD4+ cells compared to controls (Fig. 1b; all $p<0.05)$.

Expression of CD40 ligand (CD40L) and CD69 is upregulated upon $\mathrm{T}$ cell activation. A few patients with SSc had elevated expression of these molecules on circulating $\mathrm{T}$ cells above the range seen in the healthy controls, but the SSc group overall did not show significantly elevated expression of either CD40L or CD69 (Fig. 2).

Regulatory $\mathrm{T}$ cells (Treg) are defined by co-expression of CD25 (a subunit of the interleukin 2 receptor) on the cell surface and intracellular expression of FoxP3, the canonical Treg transcription factor. Deficiencies in the numbers and/or function of Treg have been described in SSc $[9,10]$ and in other systemic rheumatic diseases [11]. However, in our clinically homogeneous population

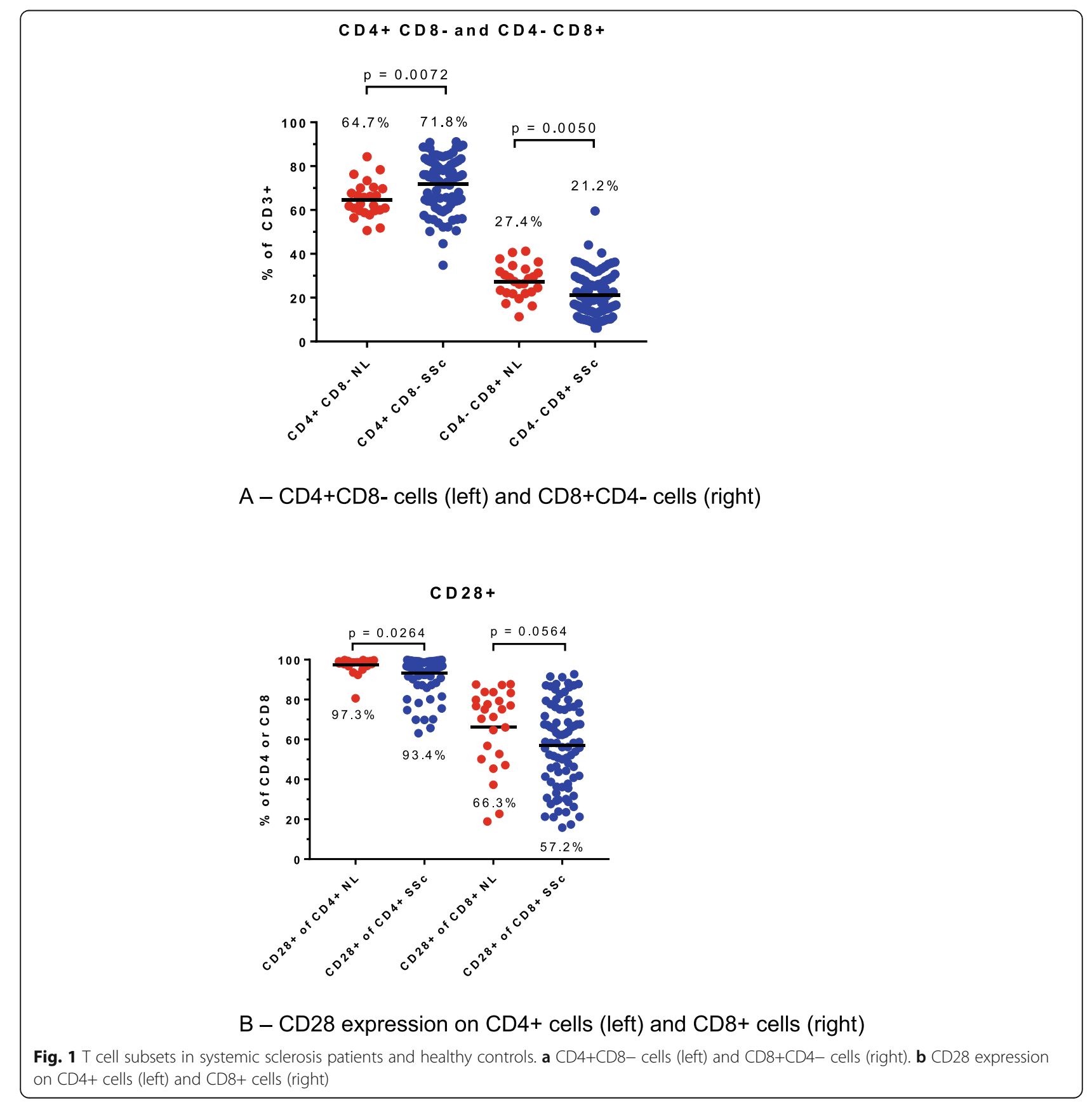




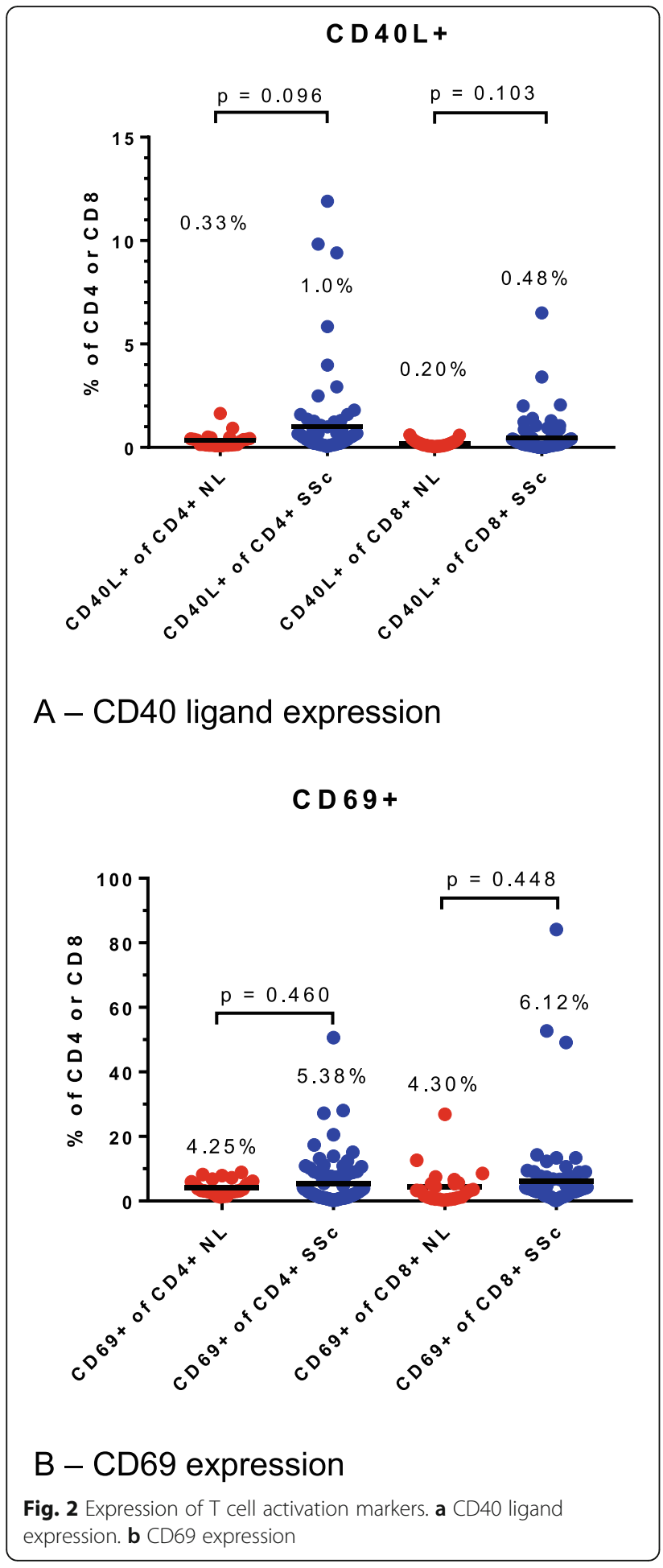

of patients with early dcSSc, the Treg number did not differ between SSc and control samples, although the range was greater in the SSc group (Fig. 3). Furthermore, the intensity of expression of FoxP3 was significantly greater in the SSc patients than in the control group (mean fluorescence intensity 2851 versus 1401, $p<$

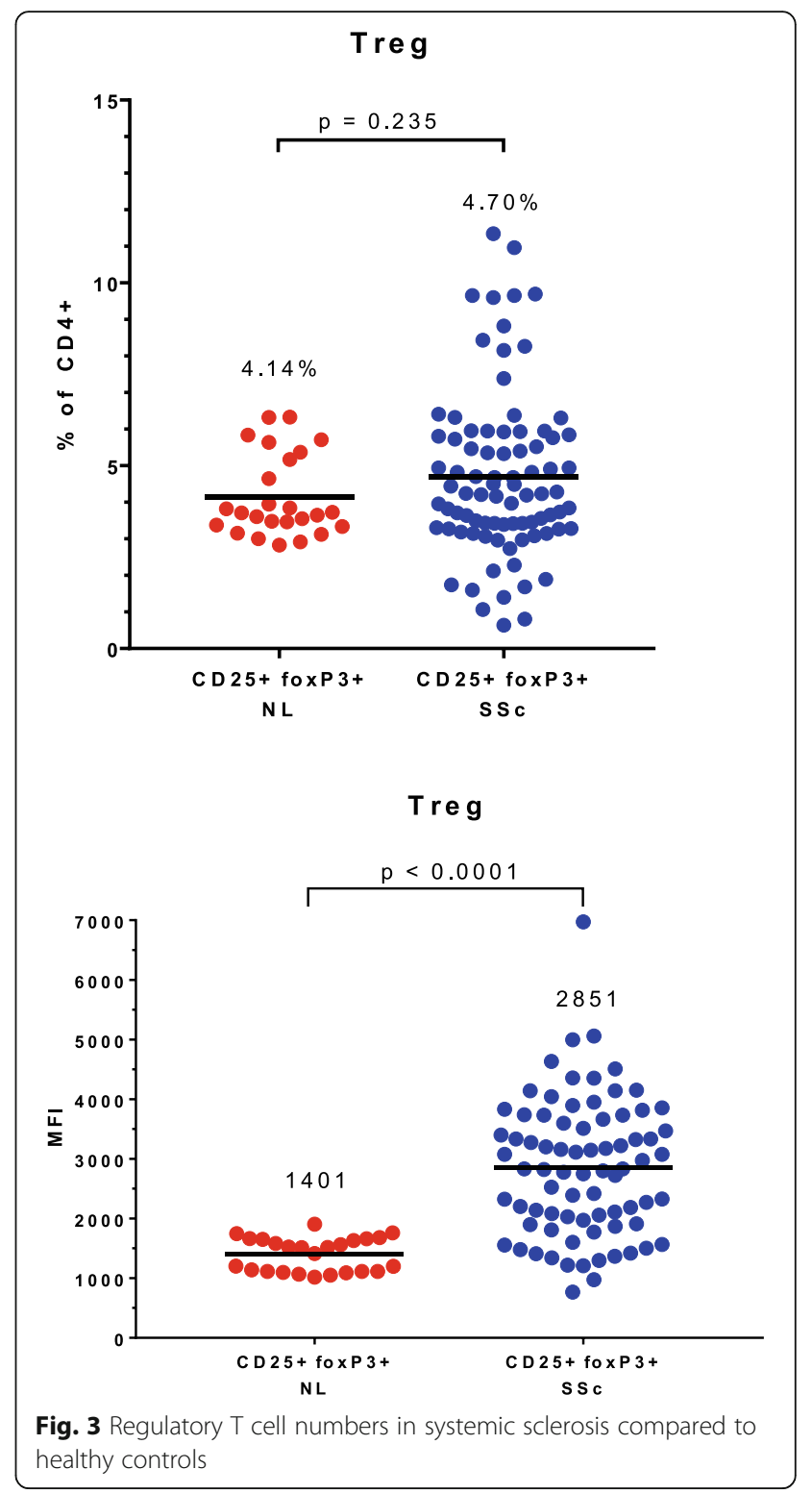

0.0001). We also measured the frequency of resting and activated Tregs in a subset of the subjects (6 patients and 6 controls) and observed no differences between the groups. As a percentage of CD4+ cells, the results were resting $\mathrm{T}$ regs (CD45RA+FoxP3-low) in $4.25 \%$ in controls, $3.63 \%$ in patients, $p=0.24$; and activated Tregs (CD45RA-FoxP3-high) in $2.61 \%$ in controls, $2.62 \%$ in patients, $p=0.97$.

The surface marker CD319, also known as SLAM F7, is normally expressed by natural killer cells, a subset of CD8+ lymphocytes and plasma cells, but by only a tiny number of normal CD4+ cells. Recently, an expansion of this subset has been noted in IgG4 disease which, like SSc, has a prominent component of fibrosis [12-14]. On non-B lineage cells, CD319 is a marker for lymphocytes with cytotoxic capabilities. We observed the presence of 
a small subset of CD4+CD319+ cells in SSc (mean $2.96 \%$ ), which was considerably expanded compared to the control group, and this difference was highly statistically significant (Fig. 4). Among CD4+ cells, most SSc patients had a CD319+ population more numerous than the upper boundary of the range seen in healthy controls.

Based on the pattern of gene expression in skin biopsies, patients with SSc can be subdivided into three molecular subsets, termed inflammatory, fibroproliferative, and normal-like. Patients enrolled in the ASSET study included individuals in each of these categories, based upon analysis of skin biopsies performed at entrance into the study [6], The percentage of CD319+ cells among the CD4+ T cells was not significantly different in the 3 groups (inflammatory $3.5 \%$, fibroproliferative $2.9 \%$, normal-like $2.4 \% ; p>$ 0.05 between any 2 of these groups). It is possible that the inflammatory subset has a greater number of CD319+CD4+ cells in total throughout the body, since migration of large numbers of these cells into the skin did not deplete the percentage in blood. Similarly, the percentage of CD4+ cells that were CD28-negative was not different between the groups (inflammatory $7.76 \%$, fibroproliferative $7.46 \%$, normallike 6.03\%).

SSc is characterized by the presence of autoantibodies, as well as by $\mathrm{T}$ cell rich lymphocytic infiltrates in target organs such as the skin. Circulating $\mathrm{T}$ cell populations of importance in the generation of antibody responses

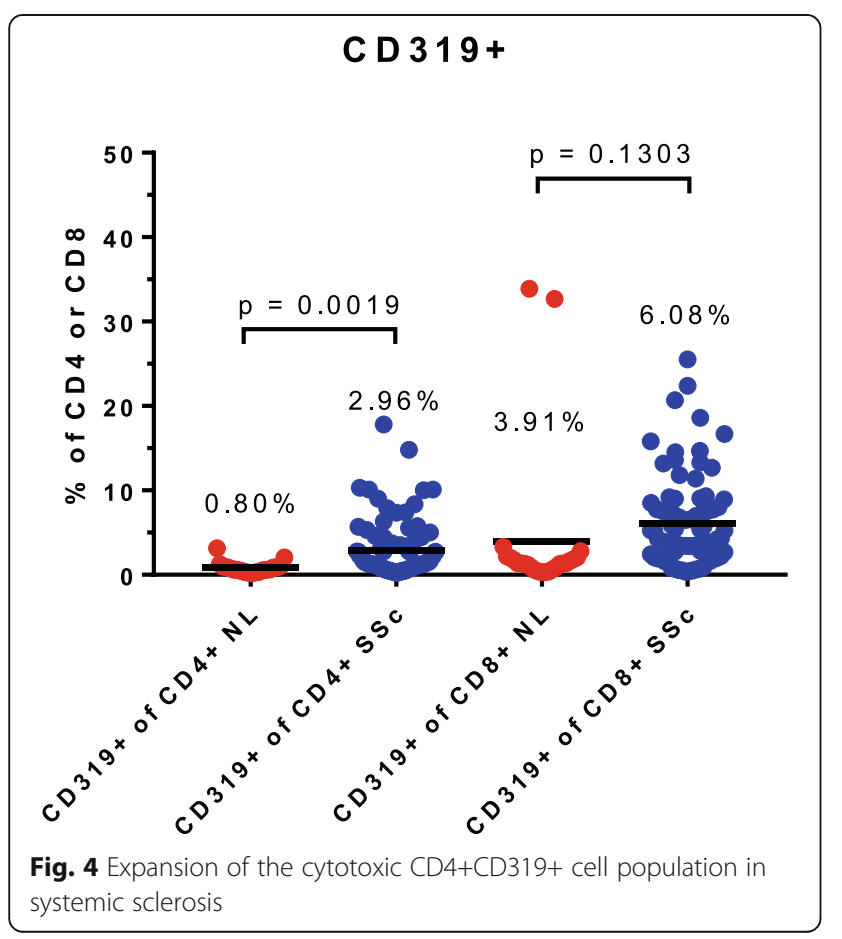

include $\mathrm{T}$ follicular helper ( $\mathrm{Tfh}$ ) cells and the recently described $\mathrm{T}$ peripheral helper (Tph) cells [15]. Tfh cells are CD4+CXCR5+PD1+ while Tph cells are CD4+ CXCR5-PD $1^{\text {high }}$. Each of these subsets was detectable in SSc peripheral blood (Fig. 5), with more Tfh but fewer Tph in SSc patients compared to controls. We also measured expression of the chemokine receptors CCR2 and CCR7 on Tph and Tfh cells. In Tph cells, we found no differences between patients and controls. However, in circulating Tfh cells, the \%+ for CCR2 was significantly lower in the patients (59\%, compared to $77 \%$ in the controls-supplementary figure). Nearly all Tfh cells expressed CCR7, mean $>98 \%+$ in both patients and controls.

The mean percentage of B lymphocytes (CD19+) in SSc samples was not significantly greater than in the controls, but more striking heterogeneity was observed in the SSc group (Fig. 6). B cells, like T cells, can be further divided into functional subsets by expression of surface structures. In this study, the CD19+ populations were subdivided using CD27 expression into naïve $\mathrm{B}$ cells (CD27neg) and memory $(\mathrm{CD} 27+)$ B cells. Within the naïve subset, an immature transitional (CD24highCD38high) population that has been reported to have immune regulatory function was measured. Memory B cells were further classified as CD24 positive and negative memory subsets, and the plasmablast subset $(\mathrm{CD} 27+\mathrm{CD} 24$ lowCD38+) was also measured. The largest differences in $\mathrm{B}$ cell subsets between controls and SSc patients were found within the CD24+ memory population and in a CD24+CD38neg subset, both of which were significantly lower in SSc patients (Fig. 6).

The data presented thus far describe lymphocyte populations identified by various subset markers, but do not directly measure functions of these cells. To measure the capacity of circulating $\mathrm{T}$ cells to produce cytokines viewed as relevant to the pathogenesis of SSc, PBMCs were activated in 24-h cultures using stimuli directed at T lymphocytes, and the synthesis of IL- 4 and IL-17 was detected by intracellular flow cytometry gated on CD4+ cells. More T cells could be classified as Th2 (IL-4 producers) than Th17 (IL-17 producers) (Fig. 7a). SSc patients did not differ from healthy controls regarding the numbers of Th2 cells, but did show expansion of Th17 cells. A small population of Th2Th17 double-lineage cells that produced both IL-4 and Il-17 was more prominent in a subset of the SSc patients. The difference between the control and SSc groups was not statistically significant by the $t$ test but was by the Wilcoxon ranksum test (Fig. 7). We also examined cytokine production by CD319+ T cells in a subgroup of 6 patients. The frequency of cytokine production (IL-4, IL-17, and also interferon-gamma) was significantly higher by CD319+ CD4+ cells compared to total CD4+ cells (Fig. 7), but 


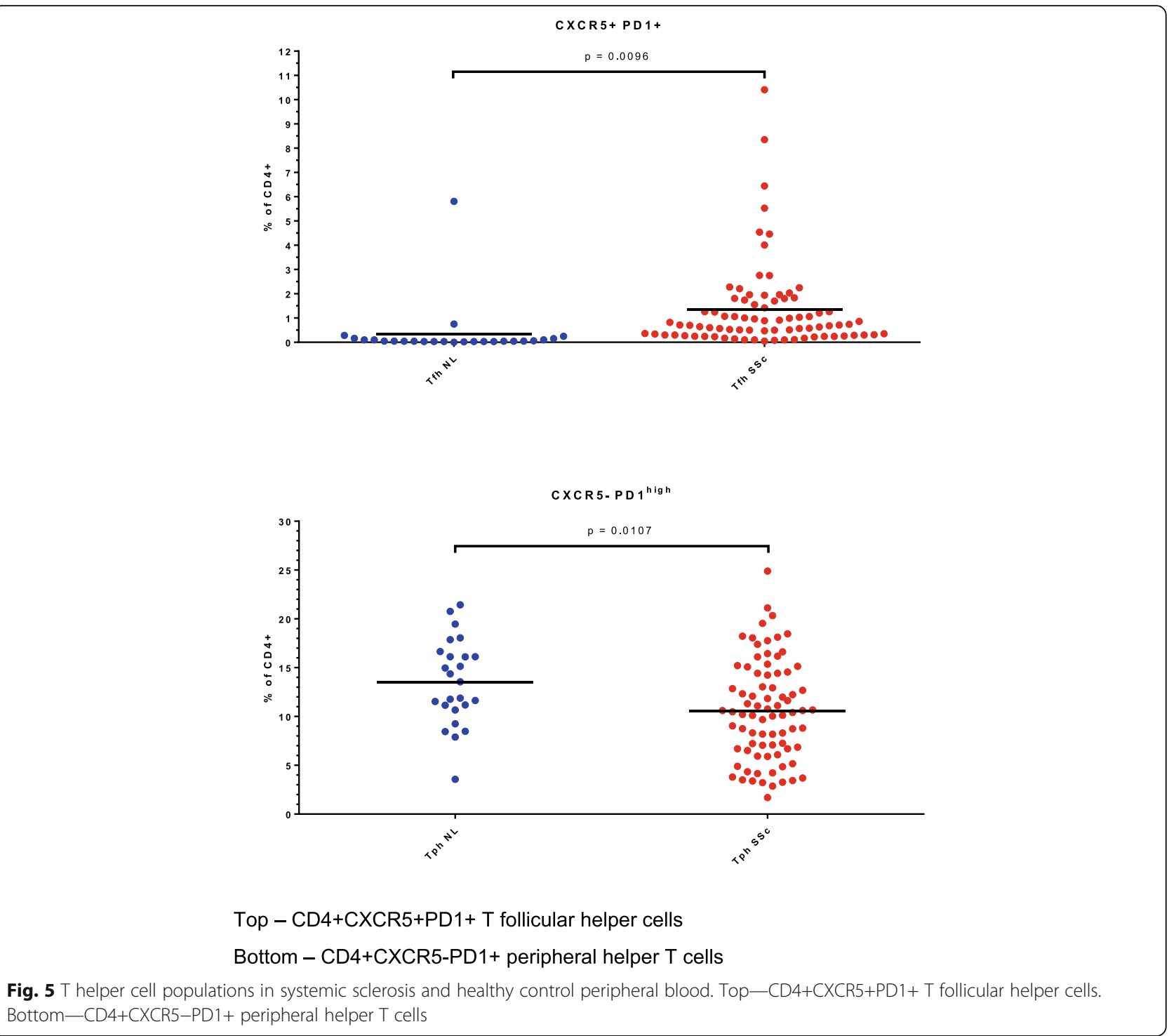

not by CD319+CD8+ cells compared to total CD8+ cells.

\section{Discussion}

Our study has several strengths and some limitations. An important feature of this study was the enrollment of a SSc cohort that was more clinically homogeneous than most prior groups of SSc patients whose immune parameters were investigated. Specifically, all of our patients had early and active dcSSc (mean disease duration, 1.59 years) without clinically significant organ involvement. Moreover, none of these patients had been treated with cytotoxic or biologic medications, and the use of low-dose corticosteroids was minimal $(14 \%$ at baseline). The absence of confounding factors due to medications or clinically significant organ involvement may account for some of the differences between our results and those from prior reports. Efforts to control for these confounding factors while analyzing lymphocyte subsets in patients with longstanding SSc who were treated with cytotoxic medications were only partly successful [16]. The analysis of patients with early disease may provide better clues to abnormalities in the immune and inflammatory pathways that lead to tissue damage and fibrosis in SSc, versus phenomena that are the consequence of fibrosis. The control samples were sexmatched. Although the control subjects were slightly younger than the SSc patients, the magnitude of the age difference was modest. Moreover, comparison of the younger versus older subjects in the control group did not identify age-associated changes that would confound the comparison with the SSc group (data not shown).

The patient samples were processed and handled in a uniform fashion, as were the control samples. This 


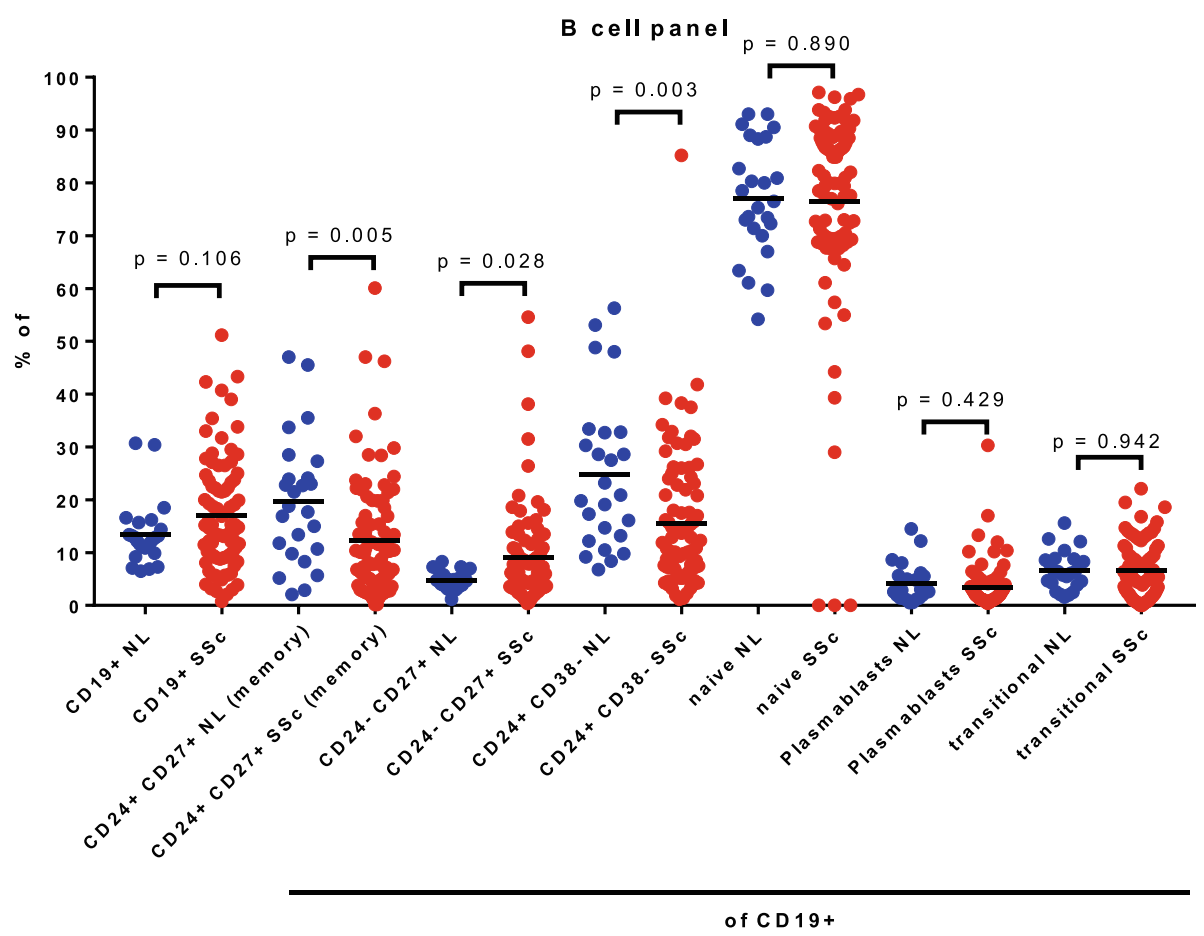

Fig. 6 B cell subsets in systemic sclerosis and control peripheral blood

involved cryopreservation of all samples, which allowed batch thawing, processing, and analysis with multiple internal controls and standards to achieve uniformity in the flow cytometry methodology. Cryopreservation may theoretically lead to non-uniform loss of cells from various lymphoid subsets, but we did not observe such phenomena in comparing fresh versus cryopreserved samples from a subset of the control subjects (data not shown). Moreover, the thawed cells were readily activated to produce cytokines.

Limitations include a restricted repertoire of functional studies that was performed, based in part on the number of cells available from patient samples. In assessing the integrity of the Treg population, for example, conclusions are ideally based not solely on the enumeration of these cells, but also on measurement of their capacity to enforce suppression of both effector cell proliferation and cytokine production.

We observed several differences between the SSc patients and the controls, some of them striking. The balance of $\mathrm{CD} 4+$ versus CD8+ $\mathrm{T}$ cells was more skewed towards the CD4+ subset in SSc. A decrease in CD8+ T cells has been previously reported in SSc, in a patient cohort weighted towards long-standing disease [17]. Expansion of the CD28negative subset was seen in our SSc patients among CD4+ $\mathrm{T}$ cells. CD4+ cells that lack CD28 are rare in blood samples from healthy subjects but are more abundant in patients with RA and have been described as oligoclonal, senescent, autoreactive, and pathogenic [18].
T cell activation markers (CD40L, CD69) were overexpressed on only a small number of SSc blood samples, but this data should not be interpreted as contradicting a critical role for $\mathrm{T}$ cells in this disease. Expression of these structures on the cell surface can be transient, and activated cells may preferentially migrate into target organs such as skin or traffic back to lymphoid tissues. Thus, the observation of a small subset of activated or functionally unusual $\mathrm{T}$ cells in the circulation can correspond to a major role for such cells in sites of disease. A relevant and striking example is the appearance in our group of patients with early dcSSc of a small but significantly expanded subset of CD4+CD319+ lymphocytes, also referred to as SLAMF7+ or cytotoxic CD4+ cells (abbreviated CD4CTL). Moreover, we show here that this CD4+CD319+ subset is significantly enriched for cells that can produce cytokines in short-term cultures. These cells have recently been identified in both IgG4 disease [12-14] and SSc skin tissue in early diffuse and limited cutaneous SSc. In SSc skin, these cells comprise $20-60 \%$ of the CD4+ cells and encircle the skin microvasculature, associated with evidence of damage to adjacent endothelial cells. They express and appear to locally discharge contents of cytotoxic granules (perforin and granzymes) [19], explaining the cellular origin of these tissue-damaging mediators that were first noted in SSc skin lesions decades ago [20].

Tregs control immune responses through multiple mechanisms, and defects in Treg numbers and/or 


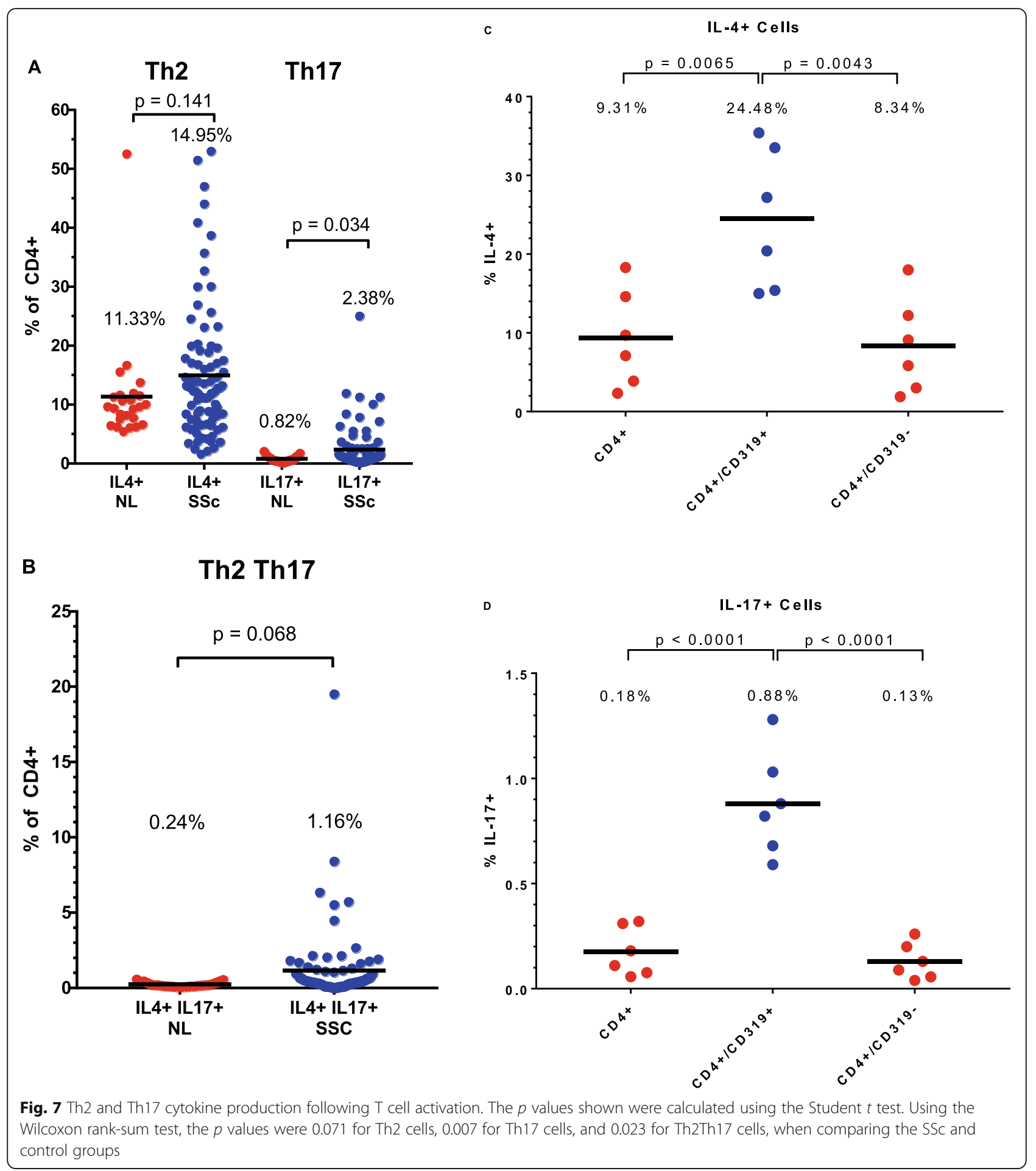

functions have been described in rheumatoid arthritis (RA), systemic lupus erythematosus, and SSc $[9,10,21]$. In SSc, increased, decreased, and normal numbers of Tregs have been reported in various studies, but function of circulating Tregs was consistently found to be deficient. In some situations, Treg defects can be reversed by successful treatment of autoimmune disease, particularly RA, by neutralization of cytokines (such as TNF or IL-6) that can impair Treg differentiation and/or functional effectiveness [22], but similar studies have not been reported in SSc. We found no difference in the mean numbers of total, activated, or resting Tregs between SSc and control subjects, although the range was much greater in the SSc samples, and many SSc patients 
had numbers of Tregs greater than or less than the limits of the range observed in the controls. The demonstration of normal Treg numbers does not establish that their function is intact and we did not assess this in the current analysis. Nevertheless, the unexpected finding of increased intensity of FoxP3 expression in Tregs of the patients argues against a functional Treg defect in patients with early, untreated SSc. Moreover, it is possible that Treg cytokines could contribute to a fibrotic diathesis in SSc.

In SSc, pathogenic roles have been attributed to both Th17 and Th2 cells, which secrete IL17 and IL4, respectively $[21,23-26]$. The number of cytokineproducing Th17 but not Th2 cells was modestly higher in this study in cultures of mononuclear cells from SSc versus controls. In addition, a small population of double-producers of IL4 and IL17 was expanded in some SSc patients. The existence of such cells is somewhat paradoxical, as IL4 typically suppresses Th17 development and cytokine secretion. However, such cells have been described in asthma [27]. In mice, antigen presentation in the lung can lead to the appearance of such cells, which originate from Th17 and not Th2 precursors [28]. Whether their presence in early diffuse SSc is a biomarker for subsequent pulmonary deterioration will require longitudinal studies. One report suggests that SSc patients with lung fibrosis had higher IL4 production by peripheral blood lymphocytes [29].

Autoantibody production in autoimmune diseases such as SSc generally requires T helper cell collaboration with autoantigen-specific B lymphocytes. Tfh cells in germinal centers of lymphoid organs are very important for $\mathrm{B}$ cell activation, differentiation, and antibody production and are present in the circulation in small numbers. We observed expansion of this subset in our SSc patients, as did a recent study that indicated Tfh expansion in a SSc cohort with average disease duration of 12 years [30]. In circulating Tfh cells the \%+ for CCR2 was significantly lower in the patients (59\%), compared to $77 \%$ in the controls. CCL2, a ligand for CCR2, is elevated in early systemic sclerosis and is a biomarker for progression of interstitial lung disease in these patients [31]. The lower percentage of CCR2+Tfh in the patients could indicate CCL2-directed migration of such cells into lymphoid tissues and/or target organs in systemic sclerosis.

Recently, a related $\mathrm{T}$ cell subset with a slightly different surface marker profile (lacking CXCR5 but expressing PD-1) has been described [15]. This subset, termed Tph ( $T$ peripheral helper) cells, are abundant in RA, both in the target organ (synovial tissue) and in the blood [32]. Expansion of this subset was also recently reported in SLE peripheral blood [32]. In each of these studies, the majority of patients had long-standing disease. Increased expression of PD-1 was found in a heterogeneous cohort of SSc patients with an average disease duration of 7.3 years (range 1 month-42 years) [33]. We detected fewer Tph cells in SSc blood than in the controls, although the numerical difference was modest. Longitudinal studies and functional analyses will be required to assess the importance of these observations.

Differences between SSc and control samples were also found using a panel of antibodies to B cell surface markers. The range of the percent of $B$ cells among total lymphocytes was far more heterogeneous than in the controls. Among the various B cell subsets, there was a significant decrease in the percentage of CD24+CD27+ memory B cells in SSc patients compared to the controls. There was also an increase in the CD24-CD27+ B cell subset, which contains activated memory B cells.

Longitudinal analysis of lymphocyte surface markers and function would potentially yield further insights and were performed on blood samples from the SSc patients but not the normal controls. These longitudinal results will be reported separately, comparing abatacept versus placebo-treated groups in the ASSET study. Further understanding of SSc, and especially of how to move towards a precision medicine approach that matches molecular subsets with ideal therapeutic targets, will hopefully emerge from detailed analysis and correlation of multiple immune, molecular, and clinical parameters in both cross-sectional and longitudinal studies.

\section{Conclusion}

A clinically homogeneous population of patients with early dcSSc was studied, whose immune parameters were not confounded by long disease duration, exposure to immunosuppressive drugs, or pre-existing organ damage. A parallel cohort of healthy controls was also studied. Numerous differences were found between the SSc patients and healthy controls in lymphocyte subset numbers and cytokine production. Most striking was expansion and heightened cytokine secretion of CD4+CD319+ cells, which are very rare in the peripheral blood of healthy individuals and which have tissue-damaging capabilities. Other abnormalities included expansion of CD4+CD28- cells, T follicular helper cells, and Th17 cells.

Disease-associated abnormalities of lymphocyte surface markers and function are thus readily identifiable in patients with early dcSSc. Some of the aberrantly expressed cell membrane molecules, especially CD319, are candidates for novel therapeutic approaches with potential for more precise targeting of pathogenic lymphocytes. 


\section{Supplementary Information}

Supplementary information accompanies this paper at https://doi.org/10. 1186/s13075-020-02383-W.

Additional file 1: Table S1. Antibodies used in flow cytometry analyses. Fig. S1. Expression of CCR2 on Th cells.

\section{Abbreviations}

SSc: Systemic sclerosis; CD: Cluster designation; SLAM: Signaling lymphocyte activation molecule; DCSSC: Diffuse cutaneous systemic sclerosis; PBMC: Peripheral blood mononuclear cells; DMSO: Dimethylsulfoxide; PBS: Phosphate buffered saline; Th: T helper cell; Treg: Regulatory T cell; FCR: Receptor for immunoglobulin constant region; IC: Intracellular; IL: Interleukin; Tfh: Follicular helper T cell; Tph: Peripheral helper T cell

\section{Acknowledgements}

ASSET study investigators and their institutional affiliations are listed below. Dinesh Khanna, MD ${ }^{1}$, Cathie Spino, ScD², Sindhu Johnson, MD, $\mathrm{PhD}^{3}$, Lorinda Chung, $\mathrm{MD}^{4}$, Michael Whitfield, $\mathrm{PhD}^{5}$, Christopher $\mathrm{P}$. Denton, $\mathrm{PhD}^{6}$, Veronica Berrocal, PhD², Jennifer Franks, BS ${ }^{5}$, Bhaven Mehta, $\mathrm{MS}^{5}$, Jerry Molitor, MD, Virginia D. Steen, $\mathrm{MD}^{8}$, Robert Lafyatis, MD ${ }^{9}$, Robert W. Simms, MD ${ }^{10}$, Anna Gill, MD ${ }^{6}$, Suzanne Kafaja, MD ${ }^{11}$, Tracy M. Frech, MD ${ }^{12}$, Vivien Hsu, MD ${ }^{13}$, Robyn T. Domsic, MD ${ }^{14}$, Janet E. Pope, MD ${ }^{15}$, Jessica K. Gordon, MD ${ }^{16}$, Maureen D. Mayes, MD $^{17}$, Elena Schiopu, MD ${ }^{1}$, Amber Young, MD ${ }^{1}$, Nora Sandorfi, MD ${ }^{18}$, Jane Park, MD ${ }^{19}$, Faye N. Hant, MD ${ }^{20}$, Elana J. Bernstein, MD ${ }^{21}$, Soumya Chatterjee, MD ${ }^{22}$, Flavia V. Castelino, MD ${ }^{23}$, Ali Ajam, MD ${ }^{24}$, Yue Wang, PhD ${ }^{5}$, Tammara Wood, MS ${ }^{5}$, Yannick Allanore, MD, PhD ${ }^{25}$, Marco Matucci-Cerinic, $\mathrm{MD}, \mathrm{PhD}^{26}$, Oliver Distler, $\mathrm{MD}^{27}$, Ora Singer, $\mathrm{MD}^{1}{ }^{1}, \mathrm{Ms}$. Erica Bush', David Fox, MD ${ }^{1}$ and Daniel E. Furst, $\mathrm{MD}^{28}$

${ }^{1}$ Division of Rheumatology, Department of Internal Medicine, University of Michigan Scleroderma Program, University of Michigan, Ann Arbor, MI, ${ }^{2}$ Biostatistics, University of Michigan, Ann Arbor, MI, ${ }^{3}$ Rheumatology, Mount Sinai Hospital and University Health Network, Toronto, ON, Canada, ${ }^{4}$ Immunology and Rheumatology, Stanford University School of Medicine, Palo Alto, CA, ${ }^{5}$ Department of Molecular and Systems Biology, Geisel Schoo of Medicine at Dartmouth, Hanover, ${ }^{6}$ UCL Division of Medicine, Royal Free Campus, London, United Kingdom, ${ }^{7}$ Rheumatic \& Autoimmune Diseases, University of Minnesota, Minneapolis, MN, ${ }^{8}$ Rheumatology, MedStar Georgetown University Hospital, Washington, DC, ${ }^{9}$ Medicine/Division of Rheumatology, Pittsburgh University Medical Center, Pittsburgh, PA, ${ }^{10}$ Rheumatology, Boston University School of Medicine, Boston, MA, ${ }^{11}$ Department of Internal Medicine, University of California Los Angeles, David Geffen School of Medicine, Division of Rheumatology, Los Angeles, CA, ${ }^{12}$ Division of Rheumatology, University of Utah, Salt Lake City, UT, ${ }^{13}$ Rheumatology, Robert Wood Johnson University Scleroderma Program, New Brunswick, NJ, ${ }^{14}$ Medicine -Rheumatology, University of Pittsburgh, Pittsburgh, PA, ${ }^{15}$ Department of Medicine, University of Western Ontario, London, ON, Canada, ${ }^{16}$ Rheumatology, Hospital for Special Surgery, New York, NY, ${ }^{17}$ Rheumatology, University of Texas McGovern Medical School, Houston, TX, ${ }^{18}$ Perelman School of Medicine, University of Pennsylvania, Pittsburgh, PA, ${ }^{19}$ Seattle Rheumatology Associates, Seattle, WA, ${ }^{20}$ Medicine/ Rheumatology \& Immunology, Medical University of South Carolina, Charleston, SC, ${ }^{21}$ Rheumatology, Columbia University, New York, NY, ${ }^{22}$ Rheumatic and Immunologic Diseases, Cleveland Clinic, Cleveland, $\mathrm{OH}$, ${ }^{23}$ Rheumatology, Harvard Medical School, Boston, MA, ${ }^{24}$ Division of Rheumatology-Immunology, The Ohio State University Wexner Medical Center, Columbus, $\mathrm{OH},{ }^{25}$ Service de Rhumatologie A, Hôpital Cochin, Paris, France, ${ }^{26}$ Department of Experimental and Clinical Medicine, University of Florence, Florence, Italy, ${ }^{27}$ Department of Rheumatology, University Hospital Zurich, Zurich, Switzerland, ${ }^{28}$ UCLA, Los Angeles, CA.

We thank Donna Cash for assistance with the preparation of the manuscript.

\section{Authors' contributions}

DAF, SKL, and DK designed the study. SP provided significant suggestions regarding the panel of lymphocyte surface markers selected for the study. DF and DK co-chaired the ASSET clinical protocol. MW supervised gene expression analyses of skin samples. PC, SR, RO, MG-R, and AS performed the experiments and recorded the data related to flow cytometry analyses of lymphocytes. PC, VB, EW, and CS performed statistical analyses. PC and EB coordinated administration and execution of the study. DAF, SKL, MW, PC,
VB, EW, and DK analyzed the data. DAF, SKL, PC, and DK drafted the manuscript. ASSET study investigators enrolled and followed patients in the ASSET clinical trial. All named authors reviewed and approved the manuscript.

\section{Funding}

Funding for this study was provided by the NIH Autoimmunity Centers of Excellence (ACE) Program (UM1Al10498). The ACE Publications Committee reviewed and approved this manuscript. Funding was also provided by Bristol Myers Squibb, which sponsored the ASSET trial. The data in this paper were collected and retained by the authors. The authors analyzed the data and prepared this manuscript without direction or constraint from the sponsors.

\section{Availability of data and materials}

The data in this paper were collected and retained by the authors.

\section{Ethics approval and consent to participate}

This study was approved by the University of Michigan Institutional Review Board.

\section{Consent for publication}

Not applicable

\section{Competing interests}

DAF has received grant support from Seattle Genetics, Gilead and Regeneron, unrelated to the subject of this study. He has received consultant fees from Pfizer, CSL Behring, and Juno Therapeutics, also unrelated. SKL is currently employed full-time at Systlmmune Inc. doing work unrelated to the subject of this study. There are no competing interests.

CS has received consultant fees from EICOS Sciences, Inc.

$\mathrm{SP}$ is on the SAB of Abpro Inc. but this is not related to the subject to this study.

DF has received grant support from Actelion, Amgen, BMS Corbus,

Galapagos GSK, NIH, Novartis, Pfizer, Sanofi, and Roche/Genentech. He has received consultant fees from Actelion, Amgen, BMS, Corbus, Galapagos Novartis, and Pfizer.

Dr. Khanna reports personal consultancy fees as part of clinical trials design from Acceleron, Actelion, Blade Therapeutics, Galapagos, GSK, Mitsubishi Tanabi, Sanofi-Aventis/Genzyme, and UCB Pharma and grants and personal consultancy fees from Bayer, BMS, and Genentech/Roche during the conduct of this study. He has stock options in Eicos Sciences Inc. He is funded by the $\mathrm{NIH} /$ NIAMS K24 AR063120.

MLW has received consulting fees from Bristol Myers Squib. Dr. Whitfield is a scientific founder and has received unrelated grant support from Celdara Medical LLC. He has received unrelated consulting fees from Abbvie, Acceleron, Celdara Medical, Corbus Pharmaceuticals, and BoeringerIngelheim.

PC, SR, RO, AS, EW, VJB-no competing interests.

\section{Author details}

${ }^{1}$ Division of Rheumatology, Department of Internal Medicine, Scleroderma Program, Clinical Autoimmunity Center of Excellence, University of Michigan, Ann Arbor, MI, USA. '2Department of Biomedical Data Science, Geisel School of Medicine at Dartmouth, Hanover, USA. ${ }^{3}$ Department of Biostatistics, University of California, Irvine, CA, USA. ${ }^{4}$ Department of Biostatistics, University of Michigan, Ann Arbor, USA. ${ }^{5}$ Division of Rheumatology, UCLA, Los Angeles, USA. ${ }^{6}$ Ragon Institute of MIT, MGH and Harvard, 400 Technology Square, Cambridge, MA 02139, USA.

Received: 23 March 2020 Accepted: 7 December 2020

Published online: 06 January 2021

\section{References}

1. Denton CP, Khanna D. Systemic sclerosis. Lancet. 2017;390(10103):1685-99.

2. Roumm AD, Whiteside TL, Medsger TA Jr, Rodnan GP. Lymphocytes in the skin of patients with progressive systemic sclerosis. Quantification, subtyping, and clinical correlations. Arthritis Rheum. 1984;27(6):645-53.

3. Kalogerou A, Gelou E, Mountantonakis S, Settas L, Zafiriou E, Sakkas L. Early $T$ cell activation in the skin from patients with systemic sclerosis. Ann Rheum Dis. 2005;64(8):1233-5. 
4. Assassi S, Swindell WR, Wu M, Tan FD, Khanna D, Furst DE, et al. Dissecting the heterogeneity of skin gene expression patterns in systemic sclerosis. Arthritis Rheumatol. 2015;67(11):3016-26.

5. Skaug B, Khanna D, Swindell WR, Hinchcliff ME, Frech TM, Steen VD, et al. Global skin gene expression analysis of early diffuse cutaneous systemic sclerosis shows a prominent innate and adaptive inflammatory profile. Ann Rheum Dis. 2020;79(3):379-86.

6. Khanna D, Spino C, Johnson S, Chung L, Whitfield ML, Denton CP, et al. Abatacept in early diffuse cutaneous systemic sclerosis: results of a phase I investigator-initiated, multicenter, double-blind, randomized. PlaceboControlled Trial Arthritis Rheumatol. 2020;72(1):125-36.

7. van den Hoogen F, Khanna D, Fransen J, Johnson SR, Baron M, Tyndall A, et al. 2013 classification criteria for systemic sclerosis: an American College of Rheumatology/European League against Rheumatism collaborative initiative. Arthritis Rheum. 2013:65(11):2737-47.

8. LeRoy EC, Medsger TA Jr. Criteria for the classification of early systemic sclerosis. J Rheumatol. 2001;28(7):1573-6.

9. Radstake TR, van Bon L, Broen J, Wenink M, Santegoets K, Deng Y, et al. Increased frequency and compromised function of T regulatory cells in systemic sclerosis (SSc) is related to a diminished CD69 and TGFbeta expression. PLoS One. 2009;4(6):e5981.

10. Ugor E, Simon D, Almanzar G, Pap R, Najbauer J, Nemeth P, et al. Increased proportions of functionally impaired regulatory $T$ cell subsets in systemic sclerosis. Clin Immunol. 2017;184:54-62.

11. Miao J, Zhu P. Functional defects of Treg cells: new targets in rheumatic diseases. Including Ankylosing Spondylitis Curr Rheumatol Rep. 2018;20(5): 30

12. Mattoo H, Mahajan VS, Maehara T, Deshpande V, Della-Torre E, Wallace ZS, et al. Clonal expansion of CD4(+) cytotoxic T lymphocytes in patients with IgG4-related disease. J Allergy Clin Immunol. 2016;138(3):825-38.

13. Maehara T, Mattoo H, Ohta M, Mahajan VS, Moriyama M, Yamauchi M, et al. Lesional CD4+ IFN-gamma+ cytotoxic T lymphocytes in IgG4-related dacryoadenitis and sialoadenitis. Ann Rheum Dis. 2017;76(2):377-85.

14. Della-Torre E, Bozzalla-Cassione E, Sciorati C, Ruggiero E, Lanzillotta M, Bonfiglio S, et al. A CD8alpha- subset of CD4+SLAMF7+ cytotoxic T cells is expanded in patients with lgG4-related disease and decreases following glucocorticoid treatment. Arthritis Rheumatol. 2018;70(7):1133-43.

15. Rao DA, Gurish MF, Marshall JL, Slowikowski K, Fonseka CY, Liu Y, et al. Pathologically expanded peripheral T helper cell subset drives B cells in rheumatoid arthritis. Nature. 2017:542(7639):110-4.

16. Gumkowska-Sroka O, Jagoda K, Owczarek A, Helbig G, Giemza-Stoklosa J, Kotyla PJ. Cytometric characterization of main immunocompetent cells in patients with systemic sclerosis: relationship with disease activity and type of immunosuppressive treatment. J Clin Med. 2019;8(5).

17. Almeida I, Silva SV, Fonseca AR, Silva I, Vasconcelos C, Lima M. T and NK cell phenotypic abnormalities in systemic sclerosis: a cohort study and a comprehensive literature review. Clin Rev Allergy Immunol. 2015;49(3):34769.

18. Goronzy JJ, Henel G, Sawai H, Singh K, Lee EB, Pryshchep S, et al.

Costimulatory pathways in rheumatoid synovitis and T-cell senescence. Ann N Y Acad Sci. 2005;1062:182-94.

19. Maehara T, Kaneko N, Perugino CA, Mattoo H, Kers J, Allard-Chamard H, et al. Cytotoxic CD4+ T lymphocytes may induce endothelial cell apoptosis in systemic sclerosis. J Clin Invest. 2020;130(5):2451-64.

20. Kahaleh MB, Fan PS. Mechanism of serum-mediated endothelial injury in scleroderma: identification of a granular enzyme in scleroderma skin and sera. Clin Immunol Immunopathol. 1997;83(1):32-40.

21. Almanzar G, Klein M, Schmalzing M, Hilligardt D, El Hajj N, Kneitz H, et al Disease manifestation and inflammatory activity as modulators of Th17/Treg balance and RORC/FoxP3 methylation in systemic sclerosis. Int Arch Allergy Immunol. 2016;171(2):141-54.

22. Nadkarni S, Mauri C, Ehrenstein MR. Anti-TNF-alpha therapy induces a distinct regulatory $T$ cell population in patients with rheumatoid arthritis via TGF-beta. J Exp Med. 2007;204(1):33-9.

23. Mavalia C, Scaletti C, Romagnani P, Carossino AM, Pignone A, Emmi L, et al. Type 2 helper T-cell predominance and high CD30 expression in systemic sclerosis. Am J Pathol. 1997;151(6):1751-8.

24. Truchetet ME, Brembilla NC, Montanari E, Lonati P, Raschi E, Zeni S, et al. Interleukin-17A+ cell counts are increased in systemic sclerosis skin and their number is inversely correlated with the extent of skin involvement Arthritis Rheum. 2013;65(5):1347-56.
25. Chizzolini C, Dufour AM, Brembilla NC. Is there a role for IL-17 in the pathogenesis of systemic sclerosis? Immunol Lett. 2018;195:61-7.

26. Mo C, Zeng Z, Deng Q, Ding Y, Xiao R. Imbalance between T helper 17 and regulatory $T$ cell subsets plays a significant role in the pathogenesis of systemic sclerosis. Biomed Pharmacother. 2018;108:177-83.

27. Irvin C, Zafar I, Good J, Rollins D, Christianson C, Gorska MM, et al. Increased frequency of dual-positive TH2/TH17 cells in bronchoalveolar lavage fluid characterizes a population of patients with severe asthma. J Allergy Clin Immunol. 2014;134(5):1175-86 e7.

28. Raymond M, Van VQ, Wakahara K, Rubio M, Sarfati M. Lung dendritic cells induce $T(H) 17$ cells that produce $T(H) 2$ cytokines, express GATA-3, and promote airway inflammation. J Allergy Clin Immunol. 2011;128(1):192-201 e6.

29. Dantas AT, Almeida AR, Sampaio M, Cordeiro MF, Oliveira PSS, Mariz HA, et al. Different profile of cytokine production in patients with systemic sclerosis and association with clinical manifestations. Immunol Lett. 2018; 198:12-6.

30. Ricard L, Jachiet V, Malard F, Ye Y, Stocker N, Riviere S, et al. Circulating follicular helper $T$ cells are increased in systemic sclerosis and promote plasmablast differentiation through the IL-21 pathway which can be inhibited by ruxolitinib. Ann Rheum Dis. 2019;78(4):539-50.

31. Wu M, Baron M, Pedroza C, Salazar GA, Ying J, Charles J, et al. CCL2 in the circulation predicts long-term progression of interstitial lung disease in patients with early systemic sclerosis: data from two independent cohorts. Arthritis Rheumatol. 2017;69(9):1871-8.

32. Makiyama A, Chiba A, Noto D, Murayama G, Yamaji K, Tamura N, et al. Expanded circulating peripheral helper $T$ cells in systemic lupus erythematosus: association with disease activity and B cell differentiation. Rheumatology (Oxford). 2019;58(10):1861-9.

33. Fleury $M$, Belkina AC, Proctor EA, Zammitti C, Simms RW, Lauffenburger DA, et al. Increased expression and modulated regulatory activity of coinhibitory receptors PD-1, TIGIT, and TIM-3 in lymphocytes from patients with systemic sclerosis. Arthritis Rheumatol. 2018;70(4):566-77.

\section{Publisher's Note}

Springer Nature remains neutral with regard to jurisdictional claims in published maps and institutional affiliations.
Ready to submit your research? Choose BMC and benefit from:

- fast, convenient online submission

- thorough peer review by experienced researchers in your field

- rapid publication on acceptance

- support for research data, including large and complex data types

- gold Open Access which fosters wider collaboration and increased citations

- maximum visibility for your research: over $100 \mathrm{M}$ website views per year

At $\mathrm{BMC}$, research is always in progress.

Learn more biomedcentral.com/submission 